\title{
Progress in TNM staging of pancreatic neuroendocrine tumors
}

\author{
Taymeyah Al-Toubah, Jonathan Strosberg \\ H. Lee Moffitt Cancer Center, Department of GI Oncology, Tampa, FL, USA \\ Correspondence to: Jonathan Strosberg, MD. H. Lee Moffitt Cancer Center, Department of GI Oncology, 12902 Magnolia Dr. Tampa, FL 33612, \\ USA. Email: jonathan.strosberg@moffitt.org. \\ Comment on: Zhang XF, Xue F, Wu Z, et al. Development and Validation of a Modified Eighth AJCC Staging System for Primary Pancreatic \\ Neuroendocrine Tumors. Ann Surg 2020. [Epub ahead of print]. doi: 10.1097/SLA.0000000000004039.
}

Submitted Oct 25, 2020. Accepted for publication Nov 23, 2020.

doi: 10.21037/hbsn-20-772

View this article at: http://dx.doi.org/10.21037/hbsn-20-772

In recent years, staging classifications for welldifferentiated pancreatic neuroendocrine tumors (NETs) have evolved significantly (1-3). Historical classifications, which attempted to combine clinical, pathological, and radiographic findings, were found to be overly complex. It was not until 2006 that Rindi et al. proposed a standard four-stage TNM classification, which was subsequently endorsed by the European Neuroendocrine Tumor Society (ENETS) (4). The T stage distinguished between tumors smaller than $2 \mathrm{~cm}(\mathrm{~T} 1), 2-$ $4 \mathrm{~cm}$ (T2), $>4 \mathrm{~cm}$ or invading duodenum/bile ducts (T3), and invading adjacent structures (T4). $\mathrm{N}$ and $\mathrm{M}$ stages were defined simply by the presence or absence of regional lymph nodes and distant metastases (Figure 1A). The American Joint Committee on Cancer (AJCC) seventh edition adopted a different TNM classification in 2010, derived from the staging for pancreatic adenocarcinoma. In this classification, T1 referred to a tumor $<2 \mathrm{~cm}, \mathrm{~T} 2$ referred to a tumor $>2 \mathrm{~cm}, \mathrm{~T} 3$ referred to disease extending beyond the pancreas, and $\mathrm{T} 4$ referred to the invasion of the celiac axis or SMA (unresectable). As in the ENETS classification, N and $M$ stage were defined simply by the presence or absence of metastases (Figure 1B).

Although both staging classifications were prognostic in aggregate, there were manifest problems in their ability to provide adequate prognostic stratification (5). These inadequacies were identified in a 2016 analysis of the Surveillance, Epidemiology, and End-Results (SEER) database and a multicentric analysis of Chinese and US institutions in which prognostic overlap was found between ENETS stages I and II and also between AJCC stages III and IV (3). Moreover, the percentage of patients with AJCC stage
III (locally advanced, unresectable) was only $2.2 \%$, reflecting the relative rarity of this presentation in pancreatic NETs. This analysis proposed a relatively simple modification: adoption of the ENETS T-definitions but the use of the AJCC stage groupings. This change resulted in a more robust prognostic classification than either the ENETS or the AJCC staging systems. Unfortunately, this proposal was not published in time for the AJCC eighth edition [2018], which adopted the ENETS classification without modification.

With this background in mind, the new modified eighth AJCC staging classification proposed by Zhang et al. published in the Annals of Surgery, offers an even more accurate prognostic staging classification (Figure 2) (6). It retains the ENETS/AJCC T-definitions but adjusts stages: for example, stage IIA (T2N0) becomes stage IB. More importantly, the new modified staging recommendation adds a new N2 category, defined as the involvement of $\geq 4$ locoregional lymph nodes. The new proposal was tested on data from the SEER registry and validated in a multiinstitutional database: the US Neuroendocrine Tumor Study Group (US-NETSG), which analyzed 825 patients who underwent curative-intent resection for grade 1 and 2 pancreatic NETs between the years 2000 and 2016. In both the SEER and US-NETSG databases, the new TNM classification resulted in a statistically significant separation of 5 -year overall survival outcomes between each stage $(\mathrm{P}<0.001$ and $\mathrm{P}<0.05$ for all stage comparisons within the SEER and US-NETSG respectively).

One might inquire about the significance of this research: why is an accurate staging system important for pancreatic NETs? One answer is that understanding how stage correlates with risk of post-surgical recurrence 
A

T1 Tumor limited to the pancreas, $<2 \mathrm{~cm}$

T2 Tumor limited to the pancreas $2-4 \mathrm{~cm}$

T3 Tumor limited to the pancreas size $>4 \mathrm{~cm}$

or invading duodenum or bile duct.

T4 Tumor invading adjacent organs or the wall of large vessels

N0 No regional lymph node metastasis N1 Regional lymph node metastasis

MO No distant metastasis

M1 Distant metastasis

$\begin{array}{llll}\text { Stage } & \text { T } & \text { N } & \text { M } \\ \text { I } & \text { T1 } & \text { N0 } & \text { M0 } \\ \text { IIA } & \text { T2 } & \text { N0 } & \text { M0 } \\ \text { IIB } & \text { T3 } & \text { N0 } & \text { M0 } \\ \text { IIIA } & \text { T4 } & \text { N0 } & \text { M0 } \\ \text { IIIB } & \text { Any T } & \text { N1 } & \text { M0 } \\ \text { IV } & \text { Any T } & \text { Any N } & \text { M1 }\end{array}$

B

T1 Tumor limited to the pancreas, $<2 \mathrm{~cm}$

T2 Tumor limited to the pancreas $>2 \mathrm{~cm}$

T3 Tumor extends beyond the pancreas but no

involvement of the celiac axis or SMA

T4 Tumor involves the celiac axis or the SMA

(unresectable)

N0 No regional lymph node metastasis

N1 Regional lymph node metastasis

M0 No distant metastasis

M1 Distant metastasis

$\begin{array}{llll}\text { Stage } & \text { T } & \text { N } & \text { M } \\ \text { IA } & \text { T1 } & \text { N0 } & \text { M0 } \\ \text { IB } & \text { T2 } & \text { N0 } & \text { M0 } \\ \text { IIA } & \text { T3 } & \text { N0 } & \text { M0 } \\ \text { IIB } & \text { T1 } & \text { N1 } & \text { M0 } \\ & \text { T2 } & \text { N1 } & \text { M0 } \\ & \text { T3 } & \text { N1 } & \text { M0 } \\ \text { III } & \text { T4 } & \text { Any N } & \text { M0 } \\ \text { IV } & \text { Any T } & \text { Any N } & \text { M1 }\end{array}$

Figure 1 ENETS (A) and AJCC 7th Edition (B) TNM staging of pancreatic NETs. ENETS, European Neuroendocrine Tumor Society; NETs, neuroendocrine tumors.

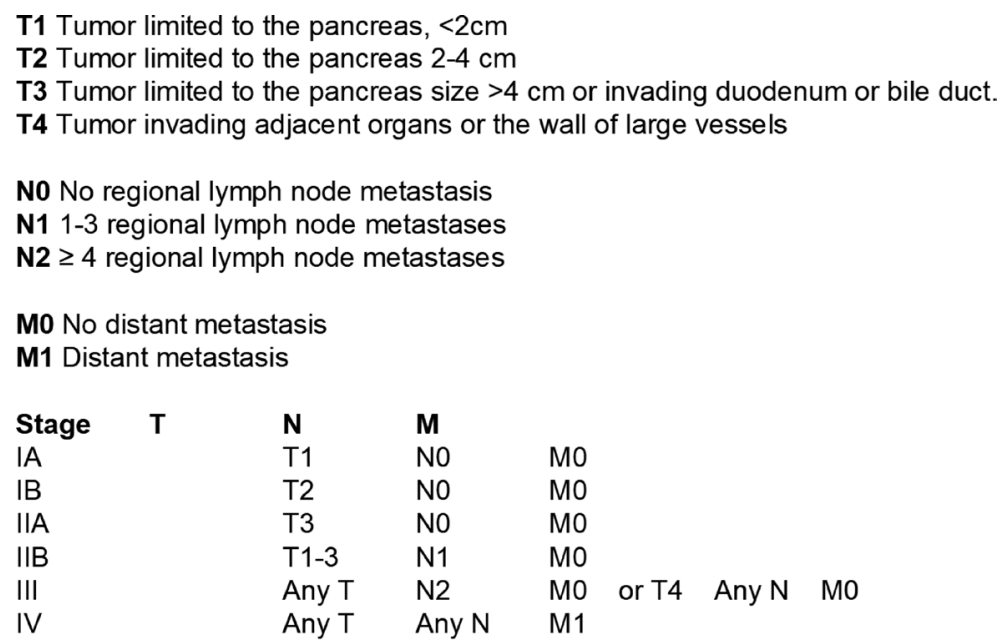

Figure 2 Proposed TNM classification for pancreatic NETs (6). NETs, neuroendocrine tumors.

and overall survival is critical as we consider the potential role of adjuvant therapy. To target adjuvant therapy to the appropriate population of patients, we need robust information on recurrence risk (already addressed by the US-NETSG and other investigators) and stage-based survival (7). Tumor grade, based on the ki-67 proliferative index and mitotic rate, is another important prognostic factor, also analyzed extensively by the US-NETSG and other groups.

In the future, molecular determinants of prognosis will undoubtedly gain in importance. One of these is a mutation in DAXX, an oncogenic driver mutation in pancreatic NETs, which seems to predict malignant behavior among patients with small, localized tumors (8). Circulating molecular 
markers will also contribute to risk stratification (9). Determination of which small $(<2 \mathrm{~cm})$, low-grade, asymptomatic tumors can be monitored safely (as opposed to resected) is a key challenge facing physicians who treat NETs (10).

In summary, Zhang and colleagues who participated in the design and validation of a new modified TNM staging system for pancreatic NETs have made significant progress in developing a new classification that stratifies survival between each stage in a statistically significant fashion. The ninth AJCC staging committee should adopt this robust yet straightforward staging classification.

\section{Acknowledgments}

Funding: None.

\section{Footnote}

Provenance and Peer Review: This article was commissioned by the editorial office, Hepatobiliary Surgery and Nutrition. The article did not undergo external peer review.

Conflicts of Interest: Both authors have completed the ICMJE uniform disclosure form (available at https://hbsn. amegroups.com/article/view/10.21037/hbsn-20-772/coif). The authors have no conflicts of interest to declare.

Ethical Statement: The authors are accountable for all aspects of the work in ensuring that questions related to the accuracy or integrity of any part of the work are appropriately investigated and resolved.

Open Access Statement: This is an Open Access article distributed in accordance with the Creative Commons Attribution-NonCommercial-NoDerivs 4.0 International License (CC BY-NC-ND 4.0), which permits the noncommercial replication and distribution of the article with the strict proviso that no changes or edits are made and the original work is properly cited (including links to both the formal publication through the relevant DOI and the license). See: https://creativecommons.org/licenses/by-nc-nd/4.0/.

Cite this article as: Al-Toubah T, Strosberg J. Progress in TNM staging of pancreatic neuroendocrine tumors. HepatoBiliary Surg Nutr 2021;10(2):238-240. doi: 10.21037/ hbsn-20-772

\section{References}

1. Bilimoria KY, Bentrem DJ, Merkow RP, et al. Application of the pancreatic adenocarcinoma staging system to pancreatic neuroendocrine tumors. J Am Coll Surg 2007;205:558-63.

2. Halperin DM, Yao JC, Dasari A. What's in a Name? Steady Progress in Staging Pancreatic Neuroendocrine Tumors. J Clin Oncol 2017;35:265-7.

3. Luo G, Javed A, Strosberg JR, et al. Modified Staging Classification for Pancreatic Neuroendocrine Tumors on the Basis of the American Joint Committee on Cancer and European Neuroendocrine Tumor Society Systems. J Clin Oncol 2017;35:274-80.

4. Rindi G, Klöppel G, Alhman H, et al. TNM staging of foregut (neuro)endocrine tumors: a consensus proposal including a grading system. Virchows Arch 2006;449:395-401.

5. Strosberg JR, Cheema A, Weber J, et al. Prognostic validity of a novel American Joint Committee on Cancer Staging Classification for pancreatic neuroendocrine tumors. J Clin Oncol 2011;29:3044-9.

6. Zhang XF, Xue F, Wu Z, et al. Development and Validation of a Modified Eighth AJCC Staging System for Primary Pancreatic Neuroendocrine Tumors. Ann Surg 2020. [Epub ahead of print]. doi: 10.1097/ SLA.0000000000004039.

7. Zaidi MY, Lopez-Aguiar AG, Switchenko JM, et al. A Novel validated recurrence risk score to guide a pragmatic surveillance strategy after resection of pancreatic neuroendocrine tumors: an international study of 1006 patients. Ann Surg 2019;270:422-33.

8. Cives M, Partelli S, Palmirotta R, et al. DAXX mutations as potential genomic markers of malignant evolution in small nonfunctioning pancreatic neuroendocrine tumors. Sci Rep 2019;9:18614.

9. Oberg K, Modlin IM, De Herder W, et al. Consensus on biomarkers for neuroendocrine tumour disease. Lancet Oncol 2015;16:e435-46.

10. Powers BD, Rothermel LD, Fleming JB, et al. A Survival Analysis of Patients with Localized, Asymptomatic Pancreatic Neuroendocrine Tumors: No Surgical Survival Benefit when Examining Appropriately Selected Outcomes. J Gastrointest Surg 2020;24:2773-9. 